\title{
River Sediment Transport Modeling of Ele River using Computational Fluid Dynamics Model of COMSOL Multiphysics Program
}

\author{
Ubah J.I. , Orakwe L.C., Okoye N.M. and Ogbu K.N. \\ Department of Agricultural and Bioresources Engineering, Nnamdi Azikiwe University Awka
}

\begin{abstract}
Excessive sediment deposition results to hydro-ecological problems particularly for shallow streams that experience significant point-source pollution. In recent times, models have been employed to investigate sediment transport in river systems. The aim of this research work is to model sediment transport of Ele River using particle tracing methodology. The governing equations of fluid flow and particle movement were modelled using COMSOL Multiphysics 5.3a. The result was validated using experimental data and the model result showed good agreement with coefficient of determination of o.99. Study results showed that sediment at the river banks posses lower velocities compared to sediments in midstream. This implies higher sediment deposition at the banks due to low flow velocity. These sediments deposition constitute problems to the river system through degradation of water quality and blocking irrigation nozzles, impacting irrigation efficiency and crop production.
\end{abstract}

Keywords: Comsol Multiphysics 5.3a; sediment transport; Computational Fluid dynamics; flow velocity

\section{INTRODUCTION}

Sediments significantly influence the flow properties of the river, because not only do sediment deposition change the natural bathymetry, they also influence volume of flow over time. Several studies have evaluated sedimentation and resuspension in water bodies (Visescu et al., 2016; Amoudry and Souza, 2011), and the negative implication of sediments deposition of water bodies have been well documented. Water quality models can be useful tools for simulating and predicting pollutant transport (Bai et al., 2011). Thus, computational fluid dynamics model using particle tracing (COMSOL Multiphysics 5.3a) will be very helpful in this work for sediment transport modelling.

Water pollution, particularly of surface water results from all activities of man which include indiscriminate waste disposal from industries such as effluents into waterways. Municipal wastes and Industrial sewages have been continuously discharged into water bodies which affect the physico-chemical quality of water, making them unfit for use by human, livestock and other organisms (Dwivedi \& Pandey, 2002).

Industrial effluents are unwanted fluids generated from industrial activities and are inappropriately discharged into the environment or receiving surface water. Its characteristics provide basic information about the utility of the rivers and streams into which they are discharged (Kanu et al., 2006). The problem posed by environmental pollution due to man's (anthropogenic) activities is fast becoming a point that should be taken seriously in today's world (Okereke, 2007).

It is noteworthy that Industries play an important role in the socio-economic development of any nation. Many industries are located near water bodies, presumably to facilitate easy disposal of effluents and other wastes into them. The perceived consequences of unregulated waste disposal into water bodies used for potable water sources has stimulated various studies on industrial effluent (Aluyor \& Badmus, 2003a; Aluyor \& Badmus, 2003b; Eletta et. al., 2005; Otukunefor \& Obiukwu, 2005; Aisien et al., 2003).

*Corresponding author's e-mail: ji.ubah@unizik.edu.ng 
Ele River in Nnewi North Local Government Area is an important water body as it serves for various purposes including agricultural and domestic needs. However, the river has continued to experience significant pollution as a result of the rapid rate of urbanization in the area and its nearness to industries, notable among them is Chicason group. Industrial waste is the most common source of water pollution in the present day (Ogedengbe and Akinbile, 2004). Industries are located at the upland through which effluents are discharged into the River located at the lowland. Sequel to this, evaluation of sedimentation and storage capacity of Ele River has become very necessary. Due to increasing computing power, the investigation of sediment transport using computer models has increased recently (G. Hillebrand et al., 2017).

However, many of the models suffer from range of problems, such as over-estimation due to uncertainty of the models and the unsuitability of assumptions and parameters in compliance with local conditions (Hajigholizadeh et al., 2018). The aim of this study is to evaluate sediment transport in Ele River Nnewi, Anambra State, Nigeria, using Computational Fluid Dynamics (CFD) code of COMSOL Multiphysics $®$ version $5.3 \mathrm{a}$, a commercial finite element software package.

\section{STUDY AREA}

Nnewi is the second largest city in Anambra State in South Eastern Nigeria. The study area Nnewi is located on Latitudes $6^{\circ} 16^{\prime} \mathrm{N}$ and $6^{\circ} 55^{\prime} \mathrm{N}$, and Longitudes $6^{\circ} 91^{\prime} \mathrm{E}$ and $6^{\circ} 55^{\prime} \mathrm{E}$. The climate is tropical. It has an average annual rainfall of $200 \mathrm{~mm}$ and mean temperature of $27^{\circ} \mathrm{C}$. The months of April to October experience heavy rainfall, while low rainfall, higher temperature and low humidity characterize the months of November to February. Ele River is an important water body as it serves for various purposes including agricultural and domestic needs. As of 2006, Nnewi has an estimated population of 391,227 according to the Nigerian census. The city spans over 1,076.9 square miles $\left(2,789 \mathrm{~km}^{2}\right)$ in Nnewi, Anambra State. Ele River is located very close to Chicason Group of Companies, Umudim Nnewi that consists of RIMCO Vegetable factory, Soap Industry, Oil and Grease Industry and Plastic Industry.
Effluents from these subsidiary industries of Chicason Group of Companies, and other nearby industries are deposited in Ele River.

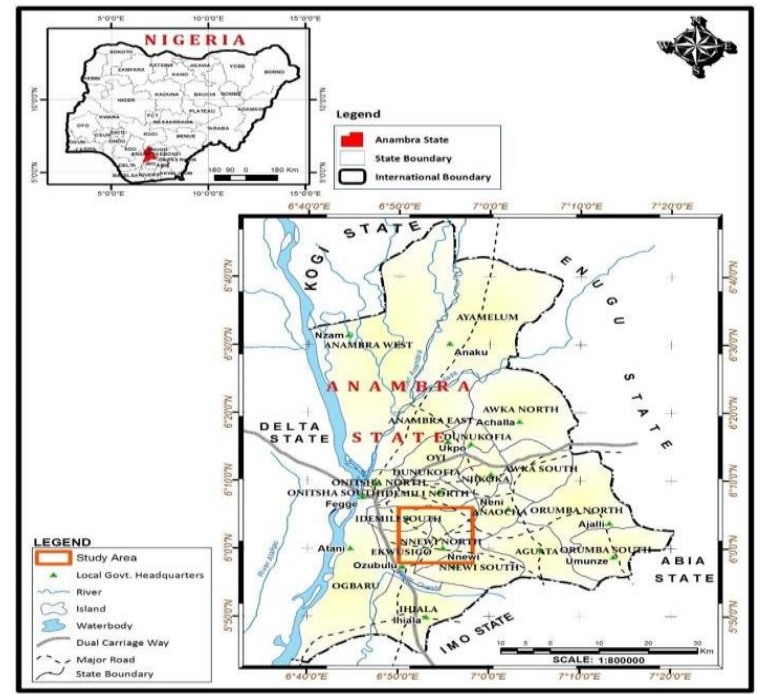

Figure 1. Nigeria showing Anambra State (top) and Anambra State showing the study area, Nnewi (bottom)

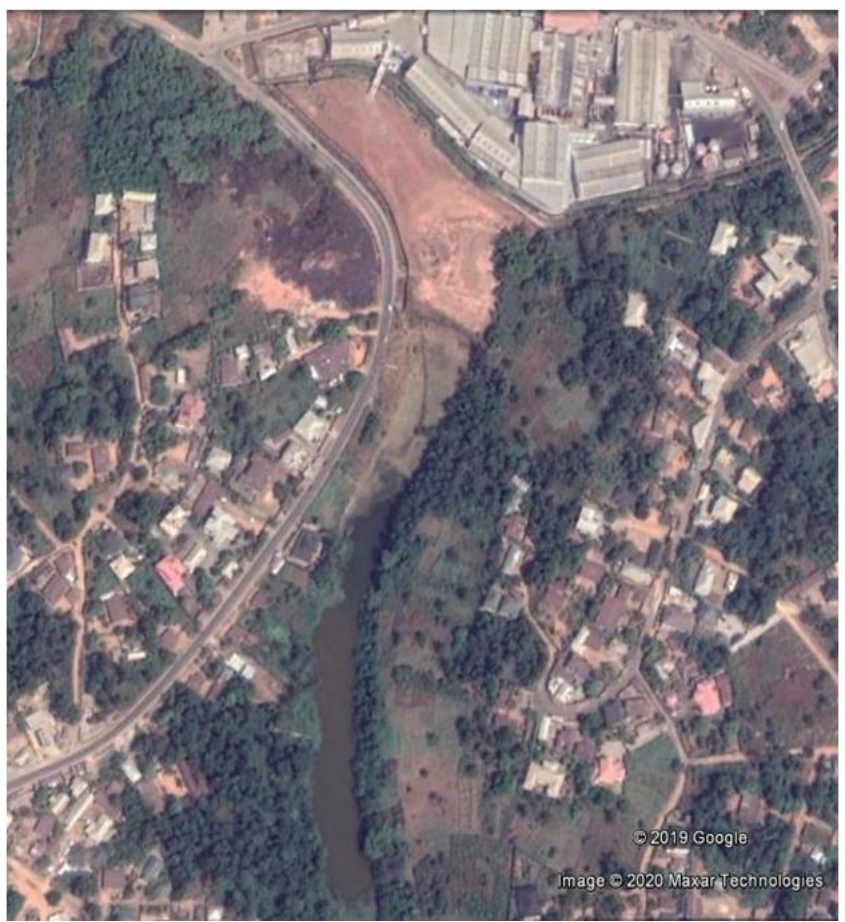

Figure 2. Visualized raster image showing Ele River and the industrial zone in Umudim Nnewi

\section{METHODOLOGY}

\section{A. Theory and Governing Equations: Flow}

The Navier-Stokes equations given below are the basis of flow dynamics in Comsol and are given as (Comsol, 2017): 
$\frac{\rho}{\partial t}+\nabla \cdot(\rho u)=0$

$\rho \frac{\partial u}{\partial t}+\rho(u . \nabla) u=\nabla \cdot[-p I+\tau]+F$

Where $\rho$ is density $(\mathrm{g} / \mathrm{ml})$; $\mathrm{u}$ is velocity; $p$ is pressure (pa); $\tau$ is viscous stress tensor $\left(\mathrm{N} / \mathrm{m}^{2}\right.$ )and $\mathrm{F}$ is volume force vector $\left(\mathrm{N} / \mathrm{m}^{3}\right)$.

Equation (1) is conservation of mass and Equation (2) is conservation of momentum. For a Newtonian fluid, which has a linear relationship between stress and strain, the viscous stress tensor is given as:

$\tau=2 \mu S-\frac{2}{3} \mu(\nabla \cdot u) I$

Where $\mu$ is the dynamic viscosity (Pa.s) and $S$ is the strainrate tensor given as:

$S=\frac{1}{2}\left(\nabla u+(\nabla u)^{T}\right)$

Thus, for a compressible flow the momentum equation becomes:

$\rho \frac{\partial u}{\partial t}+\rho u \cdot \nabla u=-\nabla p+\nabla \cdot\left(\mu\left(\nabla u+(\nabla u)^{T}\right)-\frac{2}{3} \mu(\nabla \cdot u) I\right)+F$

When the temperature variations in the flow are small, a single-phase fluid can often be assumed incompressible; that is, $\rho$ is constant or nearly constant. For constant $\rho$, the continuity equation (Equation (2)) reduces to

$\rho \nabla \cdot(u)=0$

and Equation (5) becomes:

$\rho \frac{\partial u}{\partial t}+\rho(u \cdot \nabla) u=\nabla \cdot\left[-p I+\mu\left(\nabla u+(\nabla u)^{T}\right)\right]+F$

For particle tracing, the default and most common formulation which is the Newtonian formulation was employed. It defines a set of second-order ordinary differential equations for the components of the particle position based on Newton's second law of motion, given as:

$\frac{d u}{d t}\left(m_{p} \frac{d \boldsymbol{q}}{d t}\right)=F$

Where $\mathrm{q}$ is the particle position $(\mathrm{m}), \mathrm{m}_{\mathrm{p}}$ is the particle mass $(\mathrm{kg})$, and $\mathrm{F}$ is the total force on the particles $(\mathrm{N})$.

\section{A. Data Collection}

Flow velocity was measured using Geopacks ZMFP-126S hand-held stream flow meter. Stream velocity at the inlet of the major tributary was measured at the surface midstream because flow velocity is greatest midstream and slowest along bed and banks due to friction. The measurements were carried out in the rainy season (July and August), and dry season (November and December) to account for seasonal variation in flow. Flow velocity was also measured at five points monthly in the river and at the outlet of the channel in July, for model validation. Water temperature was measured using theTeika K12 digital handheld TDS/Temp/EC meter.

\section{B. Numerical Modeling and Turbulent Flow Justification}

Two physical interfaces of Comsol Multiphysics (turbulent flow module and particle tracing module) were employed in building the model.

The turbulent flow interface was chosen because the flow conditions were within the turbulent flow regime.

Figure 2 presented the industrial cluster surrounding the River and level of sediment deposition at the banks of the River tributary which will also be shown in Figure 6 below which presents the seasonal particle transmissions. Thus, the turbulent nature of the River was not affected since the River only got reduced at its banks as a result of sediment deposition. It is worthy to note that the flow velocity and pressure distribution which contributed to the turbulent nature of the River even increased at the midstream of the River tributary, thus it does not affect its turbulent state since the kinetic or flow velocity of the River increased from the inlet through the midstream to the outlet as shown in Figure 4 for the model output for the two-dimensional velocity magnitudes in the river tributary.

Turbulence is caused by excessive kinetic energy in parts of a fluid flow, which overcomes the damping effect of the fluid's viscosity (Wikipedia). The Reynolds number quantifies the relative importance of these two types of forces (inertial forces to viscous forces) for given flow conditions, and is a guide to when turbulent flow will occur in a particular situation (Falkovich, 2011).

A 2D geometry of the major tributary of Ele River was built for this study. The georeferenced and digitized map of the river tributary was imported into Comsol. The physics controlled mesh sequence type was selected and the size of the element was set to be normal. The mesh partitions the geometric model into small units of simple shape. The generated 2D mesh of the river tributary is shown in Figure 3 . 


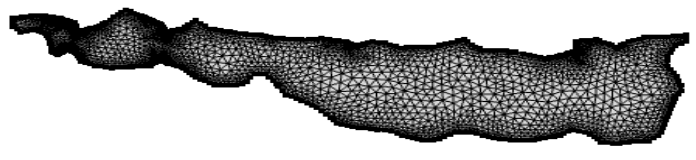

Figure 3. Generated 2D mesh of the river tributary

For turbulent flow module, inflow velocities were specified at the inlet and outlet pressure was set as $p=0$. Temperature values were also specified. While defining the boundary, no slip boundary conditions were set. For particle tracing module, the number of particles released was set at 3000. Besides inlet flow velocity and water temperature, turbulent flow module also requires water properties such as density and dynamic viscosity. These values were generated for water in Comsol as default with values set at $1000 \mathrm{~kg} / \mathrm{m}^{3}$ and 0.001 Pa.s for density and dynamic viscosity, respectively.

\section{RESULTS AND DISCUSSION}

\section{A. Velocity Distribution}

The Ele River flow was characterized by temporal pattern in the flow velocity, with higher values recorded during the rainy season compared to the dry season values. It is widely accepted that the seasonal variations of river runoff depends on climate and catchment characteristics (Lv et al., 2019). Water temperature also had a temporal pattern, with high values obtained during dry season and lower values during the rainy season. The model output for the two-dimensional velocity magnitudes in the river tributary, obtained for the different months in the first stage of simulation are visualized in Figure 4.
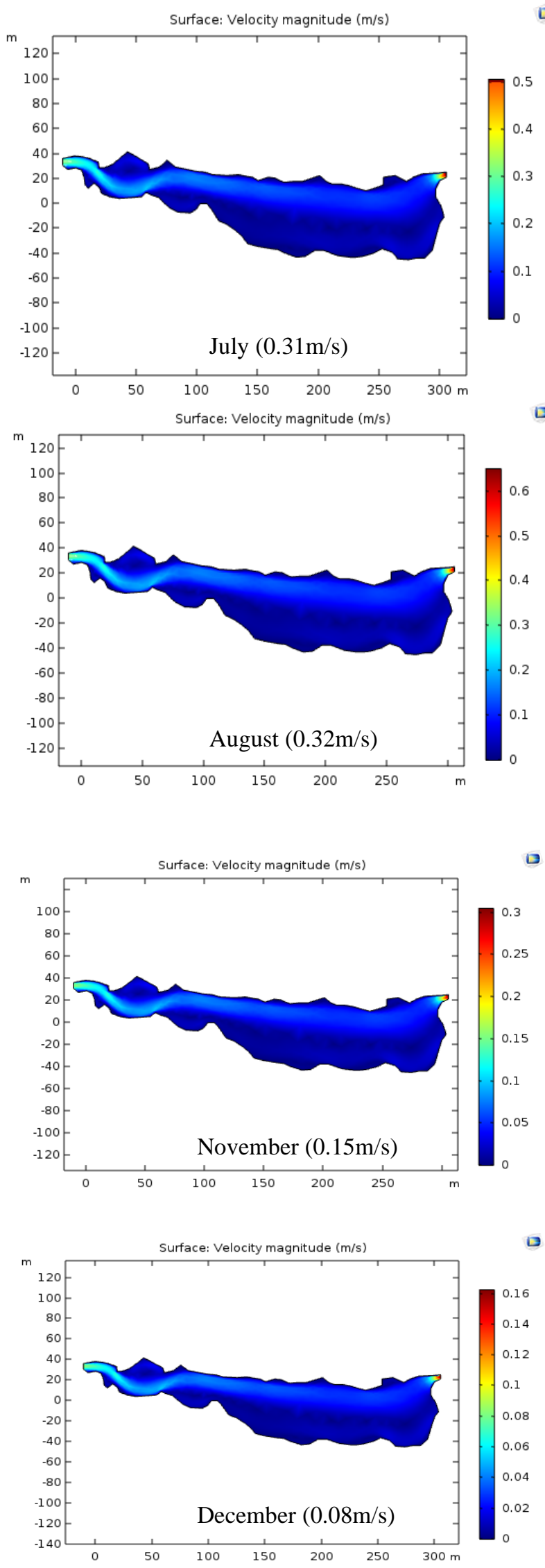

Figure 4. Flow velocity distribution for different months 
The direction of flow from the inlet towards the outlet can be identified. Furthermore, the parts of the river channel where the flow intensity was greater was clearly shown. From the 2D plot, it can be seen that dead zones (i.e., areas with very low flow velocity/ regions of stagnation) occurred close to banks of the river.

\section{B. Model Validation}

Particle transmission is basically governed by the flow velocity and as such it is enough to validate the flow velocity form the model. It is noteworthy that water quality models are very important tools to identify water environmental pollution and the final fate and behaviours of pollutants in water environment (Wang et al., 2009). To validate the model used in the simulation, measured velocity at 6 sampling points were compared to simulated flow velocity values. The values of the two velocities and their percentages difference are in presented in Table 1.

Table 1. Measured and simulated flow velocities

\begin{tabular}{cccc}
\hline $\begin{array}{c}\text { Sampling } \\
\text { Point }\end{array}$ & $\begin{array}{c}\text { Measured } \\
\text { Velocity } \\
\text { (m/s) }\end{array}$ & $\begin{array}{c}\text { Simulated } \\
\text { Velocity } \\
\text { (m/s) }\end{array}$ & $\begin{array}{c}\text { \% } \\
\text { Difference }\end{array}$ \\
\hline 1 & 0.05 & 0.0522 & 4.4 \\
2 & 0.27 & 0.2914 & 7.9 \\
3 & 0.12 & 0.1367 & 13.9 \\
4 & 0.39 & 0.4091 & 4.8 \\
5 & 0.09 & 0.0823 & 8.5 \\
6 & 0.20 & 0.2116 & 5.8 \\
\hline
\end{tabular}

The percentages difference between the measured and simulated flow velocities were in the range of $4.8 \%$ to $13.9 \%$, which is considered acceptable as it falls below the $15 \%$ tolerance suggested by Maamari et al. (2006). Apart from the percentage difference, the fit between the measured and simulated velocity was evaluated using the coefficient of determination $\left(\mathrm{R}^{2}\right)$ value. The correlation between the two velocities is presented as in Figure 5 .

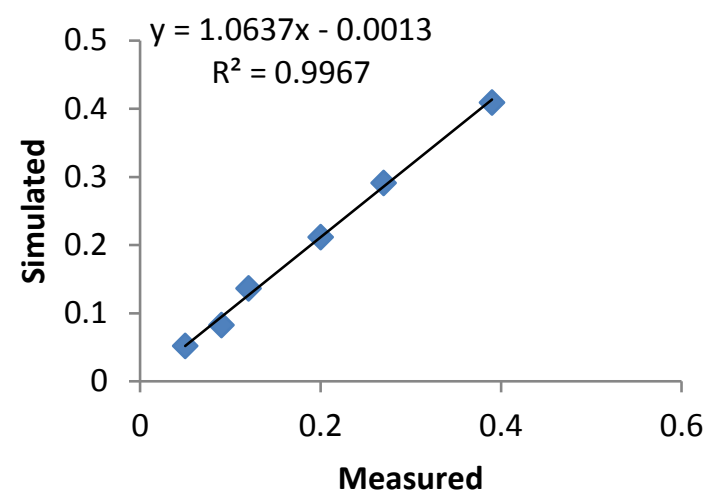

Figure 5. The correlation between the measured and simulated velocity

According to the results, simulated velocity for all the six sampled points showed good agreement with the measured velocity, with a correlation coefficient of 0.99 and thus is considered accurate for further simulations.

\section{Particle transmission}

The particles movements were influenced by the flow velocity within the channel. The results of the simulation of the trajectories of the particle from the inlet to the outlet of the river tributary for all the simulated conditions after 2000 sec simulation time are visualized in Figures 6.
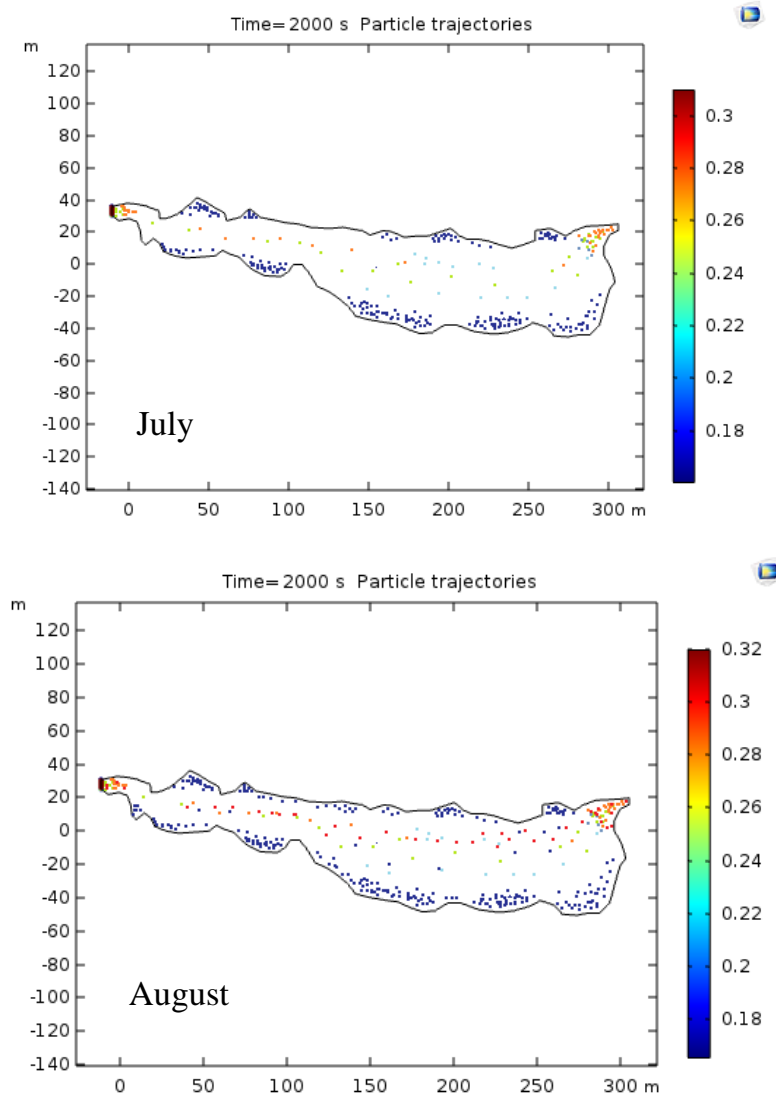

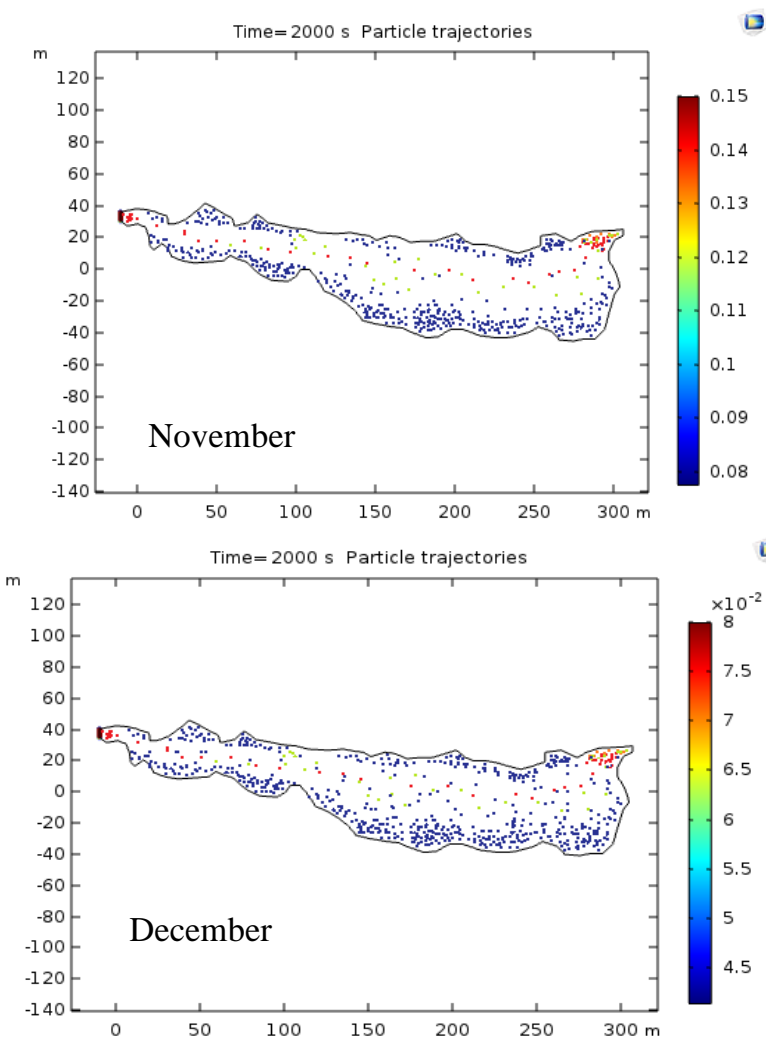

Figure 6. Particle transmission for different months

The particles trajectory provided adequate information about sediment transport in Ele River tributary. For all the simulated conditions, the particles at the banks had lower velocities compared to particles midstream. From the results of the simulation, it is evident that higher sediment deposition occurs at the banks due to stagnation. By using transmission probability function in particle tracing module, it was able to estimates the number of particles. The percentage of the particle transmitted from the inlet to the outlet after $2000 \mathrm{sec}$ simulation time was calculated. The results transmitted particles are presented in Table 2 .

Table 2. Transmission probability results

\begin{tabular}{ccc}
\hline Month & $\begin{array}{c}\text { \% of particles } \\
\text { transmitted to } \\
\text { the outlet }\end{array}$ & $\begin{array}{c}\text { \% of } \\
\text { particles } \\
\text { retained in } \\
\text { the channel }\end{array}$ \\
\hline July & 77.83 & 22.17 \\
August & 82.79 & 17.21 \\
November & 65.17 & 34.83 \\
December & 57.32 & 42.68 \\
\hline
\end{tabular}

From the Table 2, it can be seen that the percentage of particle retained in the river tributary ranged from $17.21 \%$ to
$42.68 \%$, while the number of particles transmitted to the outlet was in the range of $57.32 \%$ to $82.79 \%$. The result also revealed a seasonal trend in flow characteristic of the river, with higher number of particles retained during the dry season when the flow velocity was lowest.

\section{CONCLUSIONS}

This study employed CFD using Comsol Multiphysics software for the modelling and simulation of the flow and particle transmission in Ele River tributary. The discrepancies between the simulated and measured values were within tolerable limits. The model was able to explain $99 \%$ of the variability in the data set. Furthermore, the model was able to highlight areas with higher risk of sediment deposition, which can be used in the management of sediment load in the river. The study also found that the very low flow velocity during the dry season had a negative effect on sediment transmission in the river channel. This high sediment deposition increases the electrical conductivity and ion concentration of the River. It will also affect irrigation system for crop production considering the ability of the sediments to block sprinkler nozzles and also increase salt deposition at the crop roots zone of which will adversely affect crop production. The model can be extended to study the flow characteristics and particle transmission in the other tributaries of the Ele River.

\section{ACKNOWLEDGEMENT}

The authors acknowledge their affiliate institution, Nnamdi Azikiwe University, Awka for the enabling environment provided for this research work. 


\section{REFERENCES}

Amoudry, LO \& Souza, AJ 2011, 'Deterministic coastal morphological and sediment transport modeling: a review and discussion', Reviews of Geophysics, vol. 49, RG2002.

Aisien, FA, Aisien, ET \& Shaka, F 2003, 'The effects of rubber factory effluent on Ikpoba River', Nigerian Journal of Biomedical Engineering, vol. 2, no. 1, pp. 31-35.

Aluyor, EO \& Badmus, OAM 2003a, 'Time series analysis of pollutant levels in industrial wastewater effluent - a case study of a beverage industry', Nigerian Journal of Biomedical Engineering, vol. 3, no. 1, pp. 27-30.

Aluyor, EO \& Badmus, OAM 2003b, 'Time series analysis of pollutant levels in industrial wastewater effluents - a case study of a beverage industry', Nigerian Journal of Biomedical Engineering, vol. 2, no. 1, pp. 19-32

Bai, J, Cui, B, Chen, B, Zhang, K, Deng, W, Gao, H, Xiao, R 2011, 'Spatial distribution and ecological risk assessment of heavy metals in surface sediments from a typical plateau lake wetland, China - Ecological Modeling', vol. 222, no. 2, pp. 301-306.

COMSOL Multiphysics Reference Manual Version 5.3a (2017) COMSOL AB, USA.

Dwivedi, BK \& Pandey, GC 2002, 'Physicochemical factors and algal diversity of two ponds In Faizabad, India', Poll. Res., vol. 21, no. 3, pp. 361-370.

Eletta, OA, Adekola, FA \& Aderanti, MA 2005, 'Effects of wastewater discharge from soft drink plant into Asa River', J. Appl. Sci. Environ. Mgt., vol. 9, no. 1, pp. 187-190.

G, Hillebrand, I, Klassen \& NR, B.Olsen 2017, '3D CFD modeling of velocities and sediment transport in a hydropower reservoir', Hydrology Research, vol. 48.1.

Hajigholizadeh, M, Melesse AM \& Fuentes HR 2018, 'Erosion and sediment transport modeling in shallow waters: A review on approaches, models and applications', International Journal of Environmental Research and Public Health, vol. 15, no. 3, pp. 518.

Lv, X, Zuo, Z, Ni, Y, Sun, J \& Wang, H 2019, 'The effects of climate and catchment characteristic change on stream flow in a typical tributary of the Yellow River', Scientific reports, vol. 9, no. 1, pp. 14535. doi: 10.1038/s41598-01951115-x.

Maamari, F, Andersen, M, De Boer, J, Carroll, WD, Dumortier, D \& Greenup, P 2006, 'Experimental validation of simulation methods for bi-directional transmission properties at the day-lighting performance level', Energy and Buildings, vol. 38, no. 7, pp.878-889.

Ogedengbe, K \& Akinbile, CO 2004, 'Impact of industrial pollutants on quality of ground and surface waters at Oluyole Industrial Estate, Ibadan, Nigeria', Nigeria Journal of Technological Development, vol. 4, no. 2, pp. 139-144.

Okereke, CD 2007, 'Environmental Pollution Control', $1^{\text {st }}$ edn, Barloz Publication Owerri.

Otukunefor, TV \& Obiukwu, C 2005, 'Impact of refinery effluent on the physiochemical properties of a water body in the Niger Delta', Applied Ecology and Environmental Research, vol. 3, no. 1, pp. 61-72.

QG, Wang, WN, Dai, XH, Zhao, F, Ding, SB, Li \& Y, Zhao 2009, 'Numerical model of thermal discharge from Laibin power plant based on Mike 21', Research of Environmental Sciences, vol. 22, no. 3, pp. 332-336, (Russian).

Visescu, M, Beilicci, E \& Beilicci R 2016, 'Sediment transport modeling with advanced hydroinformatic tool case study - modeling on Bega channel sector', Procedia Engineering, vol. 161, pp. 1715-1721. 